\title{
Multiparameter Optimization of Magnetite Solid- phase Microextraction for Preconcentration of Diclofenac and Determination by UV-Vis Spectrophotometry
}

\section{Hassan Ali Shahhosseini}

Department of Chemistry, Payame Noor University

Somayeh Heydari ( $\sim$ so_heydari_83@yahoo.com )

Department of Chemistry, University of Torbat-e jam, Torbat-e jam

\section{Zarrin Es'haghi}

Department of Chemistry, Payame Noor University

\section{Leili Zare}

Department of Chemistry, Payame Noor University

\section{Original Research Full Papers}

Keywords: Central composite design, Diclofenac, Magnetic nanoparticles, Plackett-Burman design, UVVis Spectrophotometry, Magnetite solid-phase microextraction

Posted Date: February 4th, 2021

DOI: https://doi.org/10.21203/rs.3.rs-175625/v1

License: (1) (i) This work is licensed under a Creative Commons Attribution 4.0 International License. Read Full License 


\section{Abstract}

This research, aimed to synthesis and functionalize of $\mathrm{Fe}_{3} \mathrm{O}_{4}$ magnetic nanoparticles (MNPs) using dialdehyde starch and modifying with arginine amino acid. The resulting MNPs were characterized by Fourier transform infrared spectroscopy (FT-IR), Scanning electron microscope (SEM) and Vibrating sample magnetometer (VSM). Synthesized MNPs were developed for preconcentration and determination of diclofenac in biological samples by UV-Vis Spectrophotometry. A Plackett-Burman experimental design was used to evaluate the influence of effective parameters. Significant parameters were further optimized by Central Composite Design (CCD). Sample volume, pH and salting effect had a main effect on extraction of diclofenac by the proposed method. Under the optimized conditions, the detection limit $\left(3 S_{b}, \mathrm{n}=7\right)$ was found to be $0.039 \mu \mathrm{g} \mathrm{ml}^{-1}$. The calibration curve showed dynamic linear $0.05-10 \mu \mathrm{g} \mathrm{ml}^{-1}$ with correlation coefficients $\left(R^{2}\right)$ of 0.987 . The enrichment factor was found to be 148 . The proposed method showed good results for preconcentration and determination of diclofenac in serum and pharmaceutical samples.

\section{Introduction}

Diclofenac (DCF) is commonly used to relieve the symptoms of many diseases such as rheumatoid arthritis, osteoarthritis, spondylarthritis and ankylosing spondylitis [1,2] and its global consumption is estimated to be around 940 tons per annum $[3,4]$ The chemical name is 2-[(2,6-dichlorophenyl)-aminophenyl]acetic acid (Fig. 1) and it belongs to the class of nonsteroidal anti-inflammatory drugs (NSAIDs), which is commonly used in different dosage and forms such as tablets, ointments or injections [5].

During the last decade, consumption of pharmaceutical drug products has been increased to extremelevels [6] and because of their toxicity could pose threats to human health and the ecosystem. NSAIDs can be entered in almost all environmental matrices such as river water, well water, and wastewater, hence resulting in water pollution. The major sources of these water pollutions are the wastewater of pharmaceutical industries, hospital wastes or sewages and domestic wastewater [7]. Several analytical methods have been used to the determination of NSAIDsin plasma and other biological fluids, including voltammetry [8] capillary electro chromatography(CEC) [9], micellarelectrokinetic capillary chromatography (MEKC) [10], chemiluminescence [11], capillary electrophoresis [12], chromatography [13] and potentiometry [14].

In recent years, magnetic solid-phase extraction (MSPE), as a novel SPE method, has been used as a sorbent from magnetic nanoparticles (MNPs) and thus most important steps in chemical analysis have been revolted, including sample preparation and pre-concentration procedures[15, 16]. Main advantages of the Nano-sized materials in comparison to different types of sorbents in SPE method are high specific surface areas, rapid adsorption rate, highly active surface sites, inexpensive, short equilibrium time, being automatic, controllability and separating them by applying an appropriate magnetic field, non-toxicity and reusability [17-23]. 
In SPE, optimization of extraction condition (volume sample, sample ionic strength, $\mathrm{pH}$, amount of surfactant, a dose of sorbent, desorption and extraction time) is more important. Optimized procedures are usually carried out with a univariate method which means one factor at a time (OFAT). Besides being time-consuming and laboring, OFAT methods do not involve an interaction between factors. Chemometric calculations are cost-effective, useful, practical and efficient statistical approaches that can use for screening optimization of analytical procedures. These methods provide several advantages such as the reagent consumption and analysis time reduction. The most relevant multivariate techniques used in analytical optimization is response surface methodology (RSM) that is based on Plackett-Burman Design (PBD), Central Composite Design (CCD) and Design of Experiment (DOE). It can be used for calculation of affective factors simultaneously more accurate combination and evaluation in permit assessment [24, 25].

In this research, MSPE was used as a sample preparation method for separation and preconcentration of DCF which was finally analyzed by UV-Vis spectrophotometer using RSM and employing a CCD Experimental method. In order to improve the sorption capacity and selectivity of nanocomposite for DCF, L-arginine amino acid (L-Arg) was coated on the surface of magnetic dialdehyde starch (MDAS) nanocomposite and sorbent extractability of DCF was examined. In addition, seven important factors including sample volume, salt effect, $\mathrm{pH}$, amount of surfactant and sorbent, desorption and extraction time were selected to optimize.

\section{Experimental}

\subsection{Material and instrumentation}

Potato starch (food-grade) was procured from grocery. It was dried at $105^{\circ} \mathrm{C}$ before usage. Reagents include $\mathrm{NaCl}, \mathrm{FeCl}_{2} \cdot 4 \mathrm{H}_{2} \mathrm{O}, \mathrm{FeCl}_{3} \cdot 6 \mathrm{H}_{2} \mathrm{O}, \mathrm{NaIO}_{4}, \mathrm{HCl}, \mathrm{NaOH}, 2$-aminoethanol, anhydrous sodium acetate, ethylene glycol and L-arginine amino acid was obtained from Merck (Darmstadt, Germany). Methanol, Ethanol and Triton X100were procured from Samchun (Korea) and DCF was kindly donated from Pars Darou Company (Tehran, Iran).

\subsection{Apparatus}

UV-Vis Spectrophotometer (PG Instruments Ltd, model T80, UK) was used for DCF determination. The FTIR instrument (Buck Scientific, model M-500, USA) was used to characterize all MNPs. Scanning electron microscope (SEM) analysis was carried out with KYK model EM-3200, China. A metrohm pH meter (model 827, pH Lab, Swiss) equipped with a combined glass calomel electrode was used for the $\mathrm{pH}$ measurements. An ultrasonic Hielscher (model UTR200, Germany) was applied to coating the dialdehyde starch on the magnetic nanoparticles. A strong magnet $(10 \mathrm{~cm} \times 5 \mathrm{~cm} \times 2 \mathrm{~cm})$ was used for the phase separation and to determine the magnetic property of Arg-MDAS, Vibrating sample magnetometer (model MDKB, Iran) was applied. A vacuum oven (model MMM-Group) and Stirrer (model c-maths 10, IKA) were used for drying of the MNPS and agitation respectively. 


\subsection{Synthesis and characterization}

\subsubsection{Preparation of dialdehyde starch (DAS)}

DAS was synthesized according to the methods described in earlier research [26, 27]. In a typical process, sodium periodate solution ( $5.28 \mathrm{~g}$ in $100 \mathrm{ml}$ of water) as an oxidant, was added to a mixture of potato starch ( $4.0 \mathrm{~g}$ in $10 \mathrm{ml}$ of water) and adjusted $\mathrm{pH}$ to 3.5. The mixture was stirred in the dark condition at $30^{\circ} \mathrm{C}$ for $4 \mathrm{~h}$ and then filtered. DAS was washed thoroughly with deionized water for several times and ethanol (twice time). The filtered solid was dried at $50^{\circ} \mathrm{C}$ for $24 \mathrm{~h}$ under vacuum.

\subsubsection{Preparation of amine-functionalized MNPs}

Typically, $1.0 \mathrm{~g}$ of $\mathrm{FeCl}_{3} \cdot 6 \mathrm{H}_{2} \mathrm{O}$ and $2.0 \mathrm{~g}$ of anhydrous sodium acetate were added to $30 \mathrm{ml}$ of ethylene glycol, subsequently. Then $10 \mathrm{ml}$ of 2-aminoethanol was added to obtain a limpid solution via reflux. This mixture was then transferred into a Teflon-lined autoclave and heated at $200^{\circ} \mathrm{C}$ for $8 \mathrm{~h}[28,29]$. Aminefunctionalized MNPs (MNPs-NH ${ }_{2}$ ) was separated from the solution by magnet and washed with deionized water thoroughly. Finally, magnetite nanoparticles were dried at $60^{\circ} \mathrm{C}$ for $24 \mathrm{~h}$ under vacuum.

\subsubsection{Modification of MNPs- $\mathrm{NH}_{2}$ by DAS and Arg}

$0.25 \mathrm{~g}$ of DAS was added to $30 \mathrm{ml}$ of the above MNPs-NH $\mathrm{H}_{2}$ suspension (containing $0.25 \mathrm{~g} \mathrm{MNPs}-\mathrm{NH}_{2}$ ) and sonicated the suspension for 30 min with $\mathrm{N}_{2}$ protection. The reaction temperature was risen to $90^{\circ} \mathrm{C}$ for $2 \mathrm{~h}$ to obtain MNPs-NH ${ }_{2}$ dialdehyde starch nanocomposite (MDAS) [30]. Then $0.28 \mathrm{~g}$ of Arg in $15 \mathrm{ml}$ deionized water was added to the system and kept in $60^{\circ} \mathrm{C}$ for $2 \mathrm{~h}$. The resulting product, L-arginine amino acid functional magnetic dialdehyde starch nanocomposite (Arg-MDAS), was rinsed with deionizedwater and ethanol completely and dried in a vacuum oven at $60^{\circ} \mathrm{C}$ for $24 \mathrm{~h}$.

\subsection{Statistical treatment of data}

Minitab17 (Minitab Inc. USA) statistical software program was used to perform the experimental design and statistical treatment of result in the extraction. The objective of the experimental design was to determine the effective parameters on the microextraction method. The most important MSPE variables were selected and preliminary tests undertaken to assess the tendencies of the factors and which had the greatest influence on efficiency factor of DCF. A Plackett-Burman factorial design for seven variables at two levels (low and high) was set up. Most significant parameters were then selected to generate a CCD in order to build a predictive model.

\section{Results And Discussion}

\subsection{Characterization of MNPs- $\mathrm{NH}_{2}$ and Arg-MDAS}

\section{1.1 FTIR analysis}


Figure 2 shows the FTIR spectra of MNPs-NH ${ }_{2}$ and Arg-MDAS nanocomposite. The peaks in MNPs-NH spectra (a) at $1636,3406 \mathrm{~cm}^{-1}$ indicated amine group contents [31]. The peak at $588 \mathrm{~cm}^{-1}$ is related to the vibration of $\mathrm{Fe}-\mathrm{O}$ functional group, which corresponds to characteristic peak of $\mathrm{Fe}_{3} \mathrm{O}_{4}$ [32]. The peak in Arg-MDAS spectra (b) at $2334 \mathrm{~cm}^{-1}$ indicated the $\mathrm{NH}$ stretching of the terminal amino group interacted hydrogen bonding with the carboxylate residue [33]. The peak in Arg-MDAS spectra (b) at $1388 \mathrm{~cm}^{-1}$ indicated the symmetric carboxylate stretching of the arginine amino acid [34].

\subsubsection{SEM analysis}

SEM image for Arg-MDAS nanocomposite has been shown in Fig. 3. It is clearly evident that all of these MNPs were well separated from each other suggesting the $\mathrm{Fe}_{3} \mathrm{O}_{4}$ nanoparticles were free from aggregation. As can be seen, the particles have relatively uniform structure and spherical in shape and has an average diameter of about $33.33 \mathrm{~nm}$.

\subsubsection{VSM analysis}

Vibrating Sample Magnetometer used to measure the magnetic properties of MNPs-NH 2 and Arg-MDAS. The saturation magnetization curves of MNPs- $\mathrm{NH}_{2}$ and Arg-MDAS nanocomposite has been shown in Fig. 4. As shown, the MNPs-NH ${ }_{2}$ and Arg-MDAS nanocomposite have saturation magnetization of about 79.63 and $59.53 \mathrm{emu}^{-1}$ respectively. Although the magnetization due decreased after the reaction between non-magnetic materials and of MNPs- $\mathrm{NH}_{2}$. The hysteresis loop of the MNPs- $\mathrm{NH}_{2}$ and Arg-MDAS, which were measured in the powder state, indicates evidence that it is paramagnetic at room temperature, with no hysteresis.

\subsubsection{Optimization of microextraction procedure}

PBD is an efficient method for medium component optimization [35] that mostly used for twelve trials in order to appraise the effect of significant factors including $\mathrm{pH}$, sample volume, surfactant amount (Triton $\mathrm{X}-100)$, extraction and desorption time, amount of sorbent and salt effect. Each independent variable has been assessed at both high and low levels, which specified by $(+)$ and $(-)$, respectively. The variables and level of each variable displayed in Table 1. The minimum and maximum level for each factor was determined according to preliminary tests and the previous researches [36-39]. In this study, the running steps of PBD were twelve times that applied to evaluate importance of seven factors. Each experiment was repeated three times and the result shown in Table 2. The results were visualized using the Pareto chart (Fig. 5). By plotting all the results of the experiments on a Pareto chart, it would be easy to detect and compare the fundamental effects of all components. 
Table 1

Factors, codes, levels in the PBD matrix

\begin{tabular}{|llll|}
\hline Variable Code & Variable & Low(-) & Low(+) \\
\hline A & PH & 3 & 11 \\
B & Sample volume $(\mathrm{mL})$ & 3 & 10 \\
C & Extraction time $(\mathrm{min})$ & 5 & 30 \\
D & Desorption time $(\mathrm{min})$ & 5 & 15 \\
E & Surfactant amount $(\mathrm{mg})$ & 0 & 0.05 \\
F & Amount of sorbent $(\mathrm{mg})$ & 2 & 5 \\
G & Salting effect $(\%, W / \mathrm{V})$ & 0 & 10 \\
\hline
\end{tabular}

Table 2

The results of the PBD matrix

\begin{tabular}{|lllllllll|}
\hline Run Nu & A & B & C & D & E & F & G & Absorbance \\
\hline 1 & 11 & 3 & 30 & 5 & 0.00 & 2 & 10 & 0.55 \\
\hline 2 & 11 & 10 & 5 & 15 & 0.00 & 2 & 0 & 0.47 \\
3 & 3 & 10 & 30 & 5 & 0.05 & 2 & 0 & 0.75 \\
\hline 4 & 11 & 3 & 30 & 15 & 0.00 & 5 & 0 & 0.41 \\
\hline 5 & 11 & 10 & 5 & 15 & 0.05 & 2 & 10 & 0.89 \\
\hline 6 & 11 & 10 & 30 & 5 & 0.05 & 5 & 0 & 0.41 \\
\hline 7 & 3 & 10 & 30 & 15 & 0.00 & 5 & 10 & 0.95 \\
\hline 8 & 3 & 3 & 30 & 15 & 0.05 & 2 & 10 & 0.75 \\
\hline 9 & 3 & 3 & 5 & 15 & 0.05 & 5 & 0 & 0.41 \\
\hline 10 & 11 & 3 & 5 & 5 & 0.05 & 5 & 10 & 0.31 \\
\hline 11 & 3 & 10 & 5 & 5 & 0.00 & 5 & 10 & 0.88 \\
\hline 12 & 3 & 3 & 5 & 5 & 0.05 & 2 & 0 & 0.65 \\
\hline
\end{tabular}

\subsubsection{Optimization with CCD}

Response surface design is used to optimize the significant factors in experimental design. two main model designs, Box-Behnken Design (BBD) and CCD was utilized to determine the optimum levels of 
significant factors and investigate the interaction effects between most important factors of them [40].

The three factors including $\mathrm{pH}$, sample volume and salting effect had the most effect on process. Other parameters which had low importance affecting on signal were selected to be a 30 min extraction time, 15 min desorption time, $5 \mathrm{mg}$ of sorbent and the surfactant amount was not significant and removed. The mathematical relationship between the main factors, the interaction between same and different main factors can be approximated by the second-order polynomial model.

$Y=b_{0}+b_{1} B+b_{2} G+b_{3} A+b_{4} B^{2}+b_{5} G^{2}+b_{6} A^{2}+b_{7} B * G+b_{8} B * A+b_{9} G * A$

In which:

$b_{0}=-2.570 \quad b_{1}=+0.1798 \quad b_{2}=+0.0628 \quad b_{3}=+1.380 \quad b_{4}=-0.00031$

$b_{5}=-0.00203 \quad b_{6}=-0.2113 \quad b_{7}=-0.00232 \quad b_{8}=-0.03067 \quad b_{9}=-0.00110$

In this equation, $\mathrm{Y}$ is the predicted response and $\mathrm{A}, \mathrm{B}$ and $\mathrm{G}$ are $\mathrm{pH}$, sample volume and salting effect respectively. The $b_{0}$ is the model constant and $b_{1}$ to $b_{9}$ represent the regression coefficients (uncoded units). The regression coefficients show that the $\mathrm{pH}$ is the most significant compared to other factors.

The regression coefficients show positive values for three main factors, $\mathrm{pH}$, sample volume and salting effect. Comparison of interaction between the two similar main factors shows that the effect of $\mathrm{pH}$ is larger than two other factors and has a negative value. The results also indicate that the interaction between the sample volume and $\mathrm{pH}$ is more significant than interaction between other main factors, and the interaction between sample volume and salting effect is minimally effective.

The variance analysis (ANOVA) used to study the experimental results at a $95 \%$ confidence level ( $p$-value $<0.05$ ). The model determination coefficient $R^{2}$ is a statistical scale and part of the information that is expressed as a relationship between regression equations with response variables. According to Table 3 , $R^{2}$ has a value of 0.9761 , which indicates that $97.61 \%$ of variability response could be described by the model. The adjusted $\mathrm{R}^{2}$ is the $\mathrm{R}^{2}$ value with a modification for the number of terms in a model. The values of $R^{2}(0.9761)$ and adjusted $R^{2}(0.9545)$ indicated that the response equation provided a suitable model for the CCD and the polynomial model equation fits well to response variables at the $95 \%$ confidence level. As seen, the P-value of lack of fit (LOF) of 0.003 indicated that the LOF was not significant relative to the pure errors. The variance analysis of the model and the insignificant lack of fit indicate that the accuracy and the fitness of the model were highly satisfactory. 
Table 3

The result for analysis of variance

\begin{tabular}{|c|c|c|c|c|c|}
\hline Source & DF & Adj MS & Adj SS & F-Value & P-Value \\
\hline B & 1 & 30.66 & 30.66 & 111.980 & 0.000 \\
\hline G & 1 & 0.462 & 0.4623 & 1.690 & 0.009 \\
\hline A & 1 & 42.189 & 42.1892 & 154.08 & 0.000 \\
\hline$B * B$ & 1 & 0.002 & 0.0023 & 0.010 & 0.929 \\
\hline$G * G$ & 1 & 0.711 & 0.7115 & 2.600 & 0.138 \\
\hline$A^{\star} A$ & 1 & 12.286 & 12.2855 & 44.870 & 0.000 \\
\hline$B * G$ & 1 & 0.966 & 0.966 & 3.530 & 0.090 \\
\hline$B^{\star} A$ & 1 & 6.771 & 6.7712 & 24.730 & 0.001 \\
\hline$G * A$ & 1 & 0.024 & 0.242 & 0.090 & 0.772 \\
\hline LOF & 5 & 2.595 & 0.5189 & 18.080 & 0.003 \\
\hline Pure error & 5 & 0.144 & 0.0287 & & \\
\hline \multirow[t]{3}{*}{ Total error } & 19 & 114.347 & & & \\
\hline & & & R-sq & R-sq (adj) & R-sq (pred) \\
\hline & & & 97.61 & $95.45 \%$ & $80.66 \%$ \\
\hline
\end{tabular}

\subsection{Evaluation of method performance}

\subsubsection{Method validation}

Under the optimum conditions, merit Figurers were considered and the analytical characteristics of the study were exhibited in Table 4. Calibration curve showed good linear regression with the equation $Y=0.064 x+0.151$. The linear range was $0.05-10 \mu \mathrm{g} . \mathrm{ml}^{-1}$, relative standard deviation (RSD) according to calibration curve calculated $1.36 \%(n=3)$. The limit of detection $\left(L O D=3 S_{b} / m\right)$ and limit of quantification $\left(\mathrm{LOQ}=10 \mathrm{~S}_{b} / \mathrm{m}\right)$ based on 5 times the standard deviation of the blank determined $0.039,0.131 \mu \mathrm{g} \cdot \mathrm{ml}^{-1}$, respectively. High preconcentration factor 148 was obtained for extraction of DCF by the proposed method. 
Table 4

Analytical characteristics of the proposed method at optimum conditions

\begin{tabular}{|ll|}
\hline Parameters & Analytical Feature \\
\hline Calibration Equation & $y=0.064 x+0.151$ \\
\hline $\operatorname{DLR}\left(\mu \mathrm{g} \mathrm{ml}^{-1}\right)$ & $0.05-10$ \\
$\mathrm{R}^{2}$ & 0.987 \\
$\operatorname{LOD}\left(\mu \mathrm{g} \mathrm{m}^{-1}\right)(\mathrm{n}=5)$ & 0.039 \\
$\operatorname{LOQ}\left(\mu \mathrm{g} \mathrm{m}^{-1}\right)(\mathrm{n}=5)$ & 0.131 \\
\hline $\operatorname{RSD} \%(\mathrm{n}=3)$ & 1.36 \\
\hline Preconcentration Factor & 148 \\
\hline
\end{tabular}

To demonstrate the preference of the proposed method, its important parameters were compared with some of the other reported results in the literature (Table 5). As could be seen, the proposed method shows the wider linear range and lower LOD and RSD.

Table 5

Comparison of obtained data using the proposed method with other reported methods for determination of DCF

\begin{tabular}{|llllll|}
\hline Extraction method & DLR $\left(\mu \mathrm{g} \mathrm{ml}^{-1}\right)$ & LOD $\left(\mu \mathrm{g} \mathrm{ml}^{-1}\right)$ & RSD & Enrichment factor & References \\
\hline LVS $^{\mathrm{a}}$ & $5-35$ & 1.4 & 4.39 & - & {$[41]$} \\
\hline SWV & $1.5-1.75$ & 0.5 & 2.49 & - & {$[42]$} \\
\hline HF-LPME-HPLC & $0.05-2$ & 0.0028 & 2.76 & 178 & {$[43]$} \\
\hline MSPE & $0.05-1.4$ & 0.015 & 2.76 & 98 & {$[44]$} \\
\hline MIP & $0.002-0.16$ & 0.00047 & 5.00 & 80 & [45] \\
\hline MSPME & $0.05-10$ & 0.039 & 1.31 & 148 & This work \\
\hline a Linear Sweep Voltametry & & & & & \\
b Square Wave Voltametry & & & & \\
\hline cHollow Fiber Liquid Phase Microextraction High-Performance Liquid Chromatography & \\
\hline
\end{tabular}




\subsubsection{Pharmaceutical and serum sample analysis}

The pharmaceutical samples were chosen from two DCF brand tablets. Five DCF tablets of each brand were carefully weighted in order to get the average weight of each tablet. Subsequently, the tablets were finely powdered and the final powder was accurately weighted to get an equivalent quantity of active material (DCF). Then it was dissolved in ethanol and sonicated for 15 min. Finally, it was filtered to avoid any suspended particles and make a sample solution of DCF. The maximum absorption wavelength $\left(\lambda_{\max }\right)$ was observed at $280 \mathrm{~nm}$ and this wavelength was adjusted for absorbance measurement.

Human serum samples were obtained from a hospital in Taybad, Iran and stored at $4^{\circ} \mathrm{C}$ until being used. The $0.5 \mathrm{ml}$ human serum sample was spiked with the analyte to get a working concentration of DCF (0.1, 2 and $6 \mu \mathrm{g} \cdot \mathrm{ml}^{-1}$ ). Then, $0.5 \mathrm{ml}$ acetonitrile was added to deproteinize the serum. The sedimented phase was separated by centrifuging at $3000 \mathrm{rpm}$ in $20 \mathrm{~min}$ and the extracted clear supernatant transferred into a beaker. Eventually, extraction and preconcentration of the DCF were carried out by the recommended procedure. The results summarized in Table 6 revealed that the proposed method has some advantages Such as being quicker, simplicity, low cost, high chemical stability and high extraction efficiency. The nonpoisonous green synthesized MNPs- $\mathrm{NH}_{2}$ was anticipated being suitable in different applicable fields, particularly in drug delivery and other biomedical applications. 
Table 6

The results of DCF determination in real samples $(n=3)$.

\begin{tabular}{|cllll|}
\hline Sample & $\begin{array}{l}\text { DCF added } \\
\left(\mu \mathrm{g} \mathrm{ml}^{-1}\right)\end{array}$ & $\begin{array}{l}\text { Found } \\
\left(\mu \mathrm{g} \mathrm{ml}^{-1}\right)\end{array}$ & RSD (\%) & Recovery (\%) \\
\hline serum & 0 & 0.500 & 1.12 & - \\
\hline 0.1 & 0.552 & 0.46 & 92.02 \\
\hline 2 & 2.520 & 0.34 & 100.8 \\
\hline 6 & 6.287 & 1.59 & 96.72 \\
\hline tablet $^{\mathrm{a}}$ & 0 & 1.998 & 2.11 & - \\
\hline & 0.1 & 2.042 & 1.15 & 97.33 \\
\hline 2 & 4.003 & 0.18 & 100.13 \\
\hline 6 & 8.007 & 0.12 & 100.11 \\
\hline tablet $^{\mathrm{b}}$ & 0 & 2.001 & 1.83 & - \\
\hline & 0.1 & 2.104 & 0.41 & 100.14 \\
\hline 2 & 3.995 & 0.25 & 99.85 \\
\hline 6 & 8.003 & 0.09 & 100.02 \\
\hline & & & \\
\hline a Diclofenac Voltadec & & & \\
\hline b Diclofenac Jalinous $^{2}$ & & & \\
\hline
\end{tabular}

\section{Conclusion}

In this study, MNPs- $\mathrm{NH}_{2}$ coated with dialdehyde starch and subsequently modified by L-arginine amino acid successfully used for preconcentration and determination of DCF in different real samples. The multivariate strategy was used as a PBD to consider main factors that affected microextraction process and then the CCD used to optimize previously selected extraction factors of DCF by MSPE. The results revealed that the proposed method has some advantages trace amount of DCF in serum and pharmaceutical samples with satisfactory results.

\section{Declarations}

\section{Acknowledgment}

The support of this research by the Payame Noor University is greatly appreciated. 


\section{References}

1. Muraoka, S., Miura, T. Life Sciences., 2003, vol. 72, no. 17, p. 1897.

2. Rezaei Kahkha, M.R., Kaykhaii, M., Afarani, M.S., Sepehri, Z. Analytical Methods., 2016, vol. 8, no. 30, p. 5978.

3. Fu, Q., Ye, Q., Zhang, J., Richards, J., Borchardt, D., Gan, J. Environmental pollution (Barking, Essex : 1987)., 2017, vol. 222, p. 383.

4. Zhang, Y., GeiÃŸen, S.-U., Gal, C., Chemosphere., 2008, vol. 73, no. 8, p. 1151.

5. Lachmann, B., Kratzel, M., Noe, C.R., Sci Pharm., 2012, vol. 80, no. 2, p. 311.

6. Es'haghi, Z., Esmaeili-Shahri, E., J Chromatogr B Analyt Technol Biomed Life Sci., 2014, vol. 973c, p. 142.

7. Ghorbani, M., Chamsaz, M., Rounaghi, G.H., Anal Bioanal Chem., 2016, vol. 408, no. 16, p. 4247.

8. Babaei, A., Afrasiabi, M., Babazadeh, M., Electroanalysis., 2010, vol. 22, no. 15, p. 1743.

9. De Rossi, A., Desiderio, C., Journal of Chromatography A., 2003, vol. 984, no. 2, p. 283.

10. Maciẽ , A., Borrull, F., Calull, M., Aguilar, C., Journal of Chromatography A., 2006, vol. 1117, no. 2, p. 234.

11. Aly, F.A., Al-Tamimi, S.A., Alwarthan, A.A., Analytica Chimica Acta., 2000, vol. 416, no. 1, p. 87.

12. PÃ@rez-Ruiz, T., MartÄtìnez-Lozano, C., Sanz, A., Bravo, E. J Chromatogr B Biomed Sci Appl., 1998, vol. 708, no. 1-2, p.249.

13. Rouini, M.-R., Asadipour, A., Ardakani, Y.H., Aghdasi, F., J Chromatogr B Analyt Technol Biomed Life Sci., 2004, vol. 800, no. 1-2, p. 189.

14. Santini, A.O., Pezza, H.R., Pezza, L., Sensors and Actuators B: Chemical., 2007, vol. 128, no. 1, p. 117.

15. Kim, T.-Y., Yamazaki, Y., Hirano, T., physica status solidi (b)., 2004, vol. 241, no. 7, p. 1601.

16. Wen, C.-Y., Xie, H.-Y., Zhang, Z.-L., Wu, L.-L., Hu, J., Tang, M., Wu, M., Pang, D. W., Nanoscale., 2016, vol. 8, no. 25, p. 12406.

17. Amiri, M., YadollahYamini, Safari, M., Asiabi, H., Microchimica Acta., 2016, vol. 183, no. 7, p. 2297.

18. Čampelj, S., Makovec, D., Drofenik, M., Journal of Magnetism and Magnetic Materials., 2009, vol. 321, no. 10, p. 1346.

19. Bagheri, H., Daliri, R., Roostaie, A., Anal Chim Acta., 2013, vol. 794, p. 38.

20. Howard, A.G., Journal of Environmental Monitoring., 2010, vol. 12, no. 1, p. 135.

21. Bagheri, H., Roostaie, A., Baktash, M.Y., Anal Chim Acta., 2014, vol. 816, p. 1.

22. Knopp, D., Tang, D., Niessner, R., Analytica Chimica Acta., 2009, vol. 647, no. 1, p. 14.

23. Barreto, I.S., Andrade, S.I.E., Cunha, F.A.S., Lima, M.B., Araujo, M.C.U., Almeida, L.F., Talanta., 2018, vol. 178, p. 384.

24. Bezerra, M.A., Santelli, R.E., Oliveira, E.P., Villar, L.S., Escaleira, L.A.I., Talanta., 2008, vol. 76, no. 5, p. 965. 
25. Nezhadali, A., Mojarrab, M., Sensors and Actuators B: Chemical., 2014, vol. 190, p. 829.

26. Ding, W., Zhao, P., Li, R., Carbohydrate polymers., 2011, vol. 83, no. 2, p. 802.

27. Yin, Q.-F., Ju, B.-Z., Zhang, S.-F., Wang, X.-B., Yang, J.-Z., Carbohydrate polymers., 2008, vol. 72, no. 2, p. 326.

28. Leyu, W., Jie, B., Lun, W., Fang, Z., Yadong, L., Chemistry - A European Journal., 2006, vol. 12, no. 24, p. 6341.

29. Xin, X., Wei, Q., Yang, J., Yan, L., Feng, R., Chen, G., et al., Chemical Engineering Journal., 2012, vol. 184, p. 132.

30. Wang, Y., Zhang, Y., Hou, C., Qi, Z., He, X., Li, Y., Chemosphere., 2015, vol. 141, p. 26.

31. Guo, S., Li, D., Zhang, L., Li, J., Wang, E., Biomaterials., 2009, vol. 30, no. 10, p. 1881.

32. Zhang, L.-H., Sun, Q., Liu, D.-H., Lu, A.-H., Journal of Materials Chemistry A., 2013, vol. 1, no. 3, p. 9477.

33. Ling, S., Yu, W., Huang, Z., Lin, Z., HaraÃ $\pm c z y k$, M., Gutowski, M., The Journal of Physical Chemistry A., 2006, vol. 110, no. 44, p. 12282.

34. Hong-bao, L., Zi-jing, L., Yi, L., Chinese Journal of Chemical Physics., 2012, vol. 25, no. 6, p. 681. 35. Abd El Aty, A.A., Wehaidy, H.R., Mostafa, F.A., Carbohydrate polymers., 2014, vol. 102, p. 261.

36. Asfaram, A., Ghaedi, M., Goudarzi, A., Ultrasonics sonochemistry., 2016, vol. 32, p. 407.

37. Liu, R.S., Tang, Y.J., Bioresource technology., 2010, 101, no. 9, p. 3139.

38. Giordano, P.C., Beccaria, A.J., Goicoechea, H.C., Bioresource technology., 2011, vol. 102, no.22, p. 10602.

39. Bahloul, L., Ismail, F., Samar, M.E.-H., Meradi, H., Energy Procedia., 2014, vol. 50, p. 1008.

40. Asfaram, A., Ghaedi, M., Dashtian, K., Ultrason Sonochem., 2017, vol. 34, p. 561.

41. Yilmaz, B., Ciltas, U., Journal of Pharmaceutical Analysis., 2015, vol. 5, no. 3, p. 153.

42. Ciltas, U., Yilmaz, B., Kaban, S., Akcay, B.K., Nazik, G., Iran J Pharm Res., 2015, vol. 14, no. 3, p. 715.

43. sadaat, m., Qomi, M., emadzadeh, s., Gholghasemi, M., Journal of Applied Chemical Research, 2018, vol. 12, no. 1, p. 16.

44. Ershad, S., Razmara, A., Pourghazi, K., Amoli-Diva, M., Institution of Engineering and Technology., 2015, Vol. 10, no. 7, p. 358.

45. Fernández-Llano, L., Blanco-López, M.C., Lobo-Castañón, M.J., Miranda-Ordieres, A.J., Tuñón-Blanco, P., Electroanalysis., 2007, vol. 19, no. 15, p. 1555.

\section{Figures}




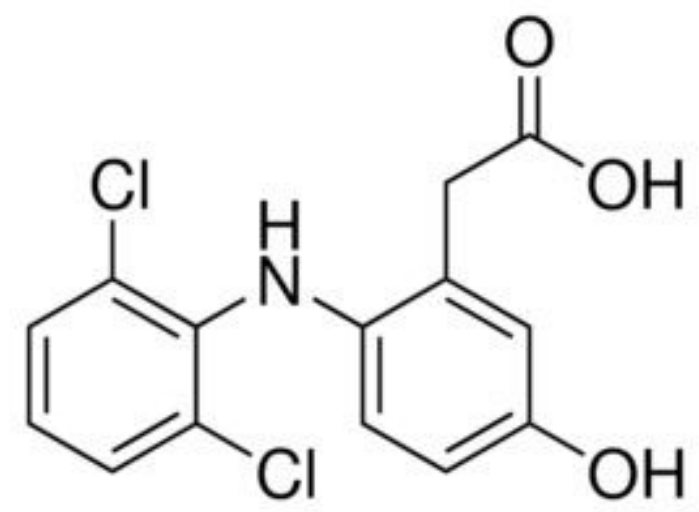

Figure 1

Chemical structures of sodium Diclofenac

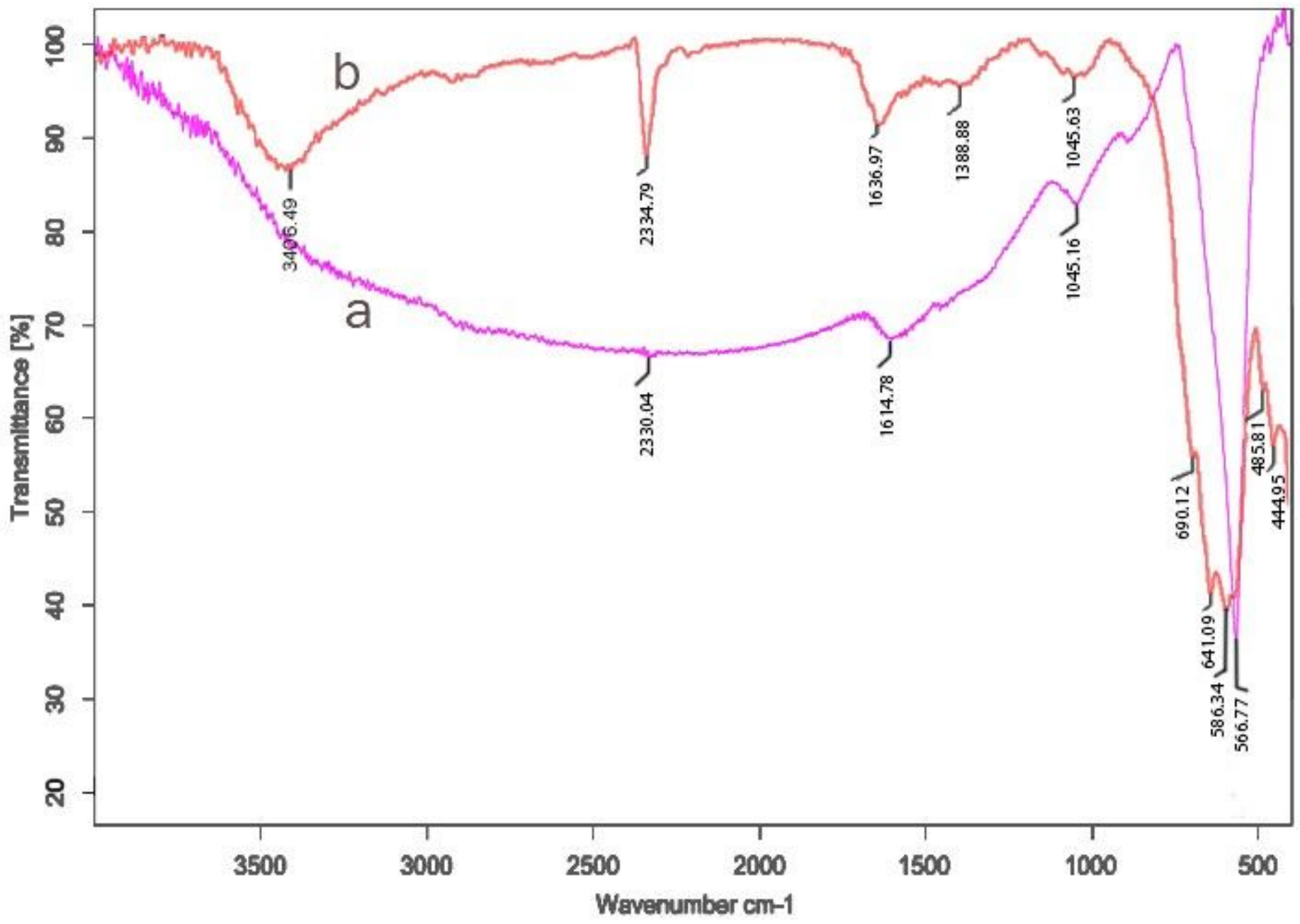

Figure 2

FTIR spectrum of MNPs-NH2 (a) and Arg-MDAS (b) 


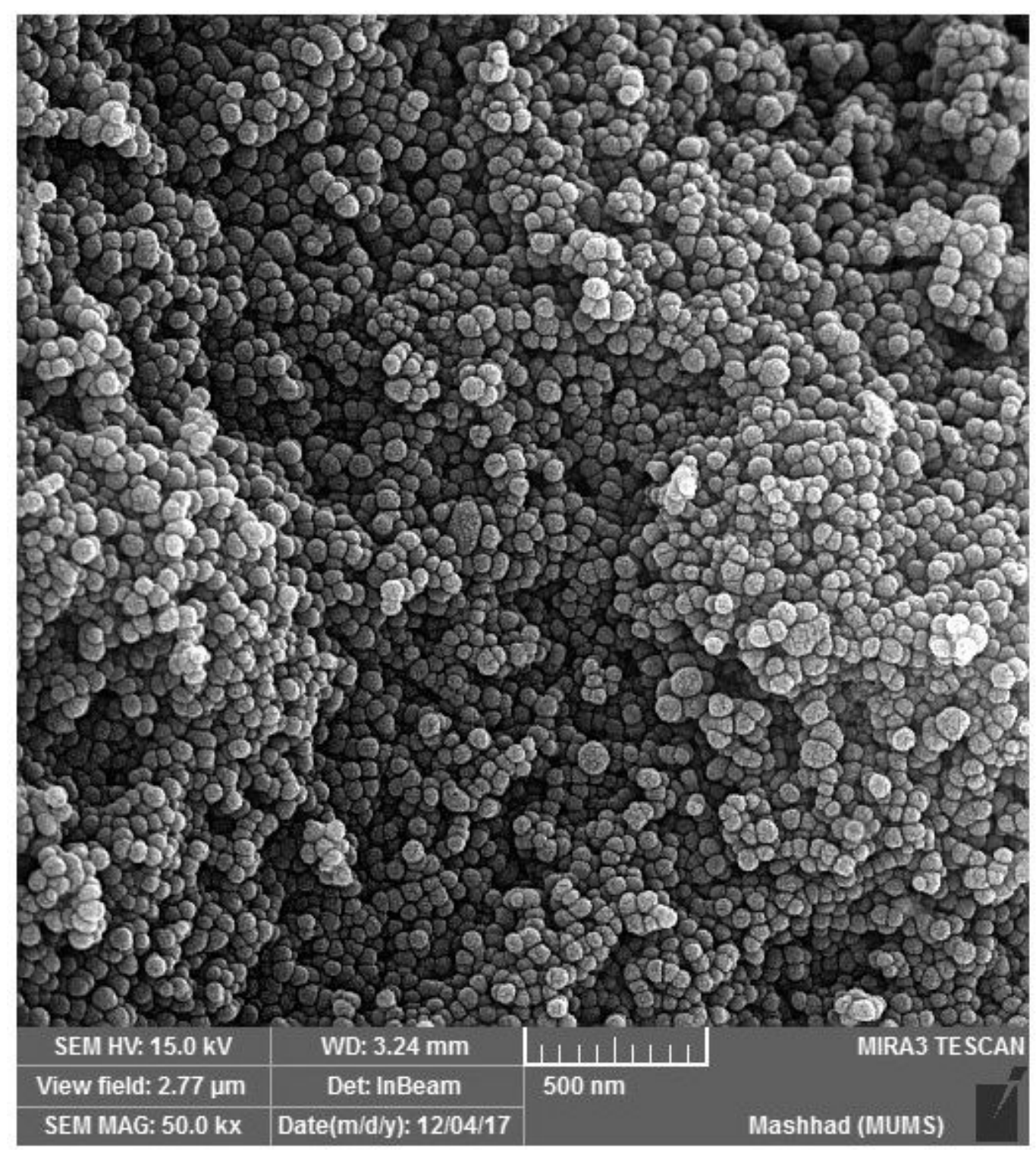

\section{Figure 3}

SEM image of Arg-MDAS 


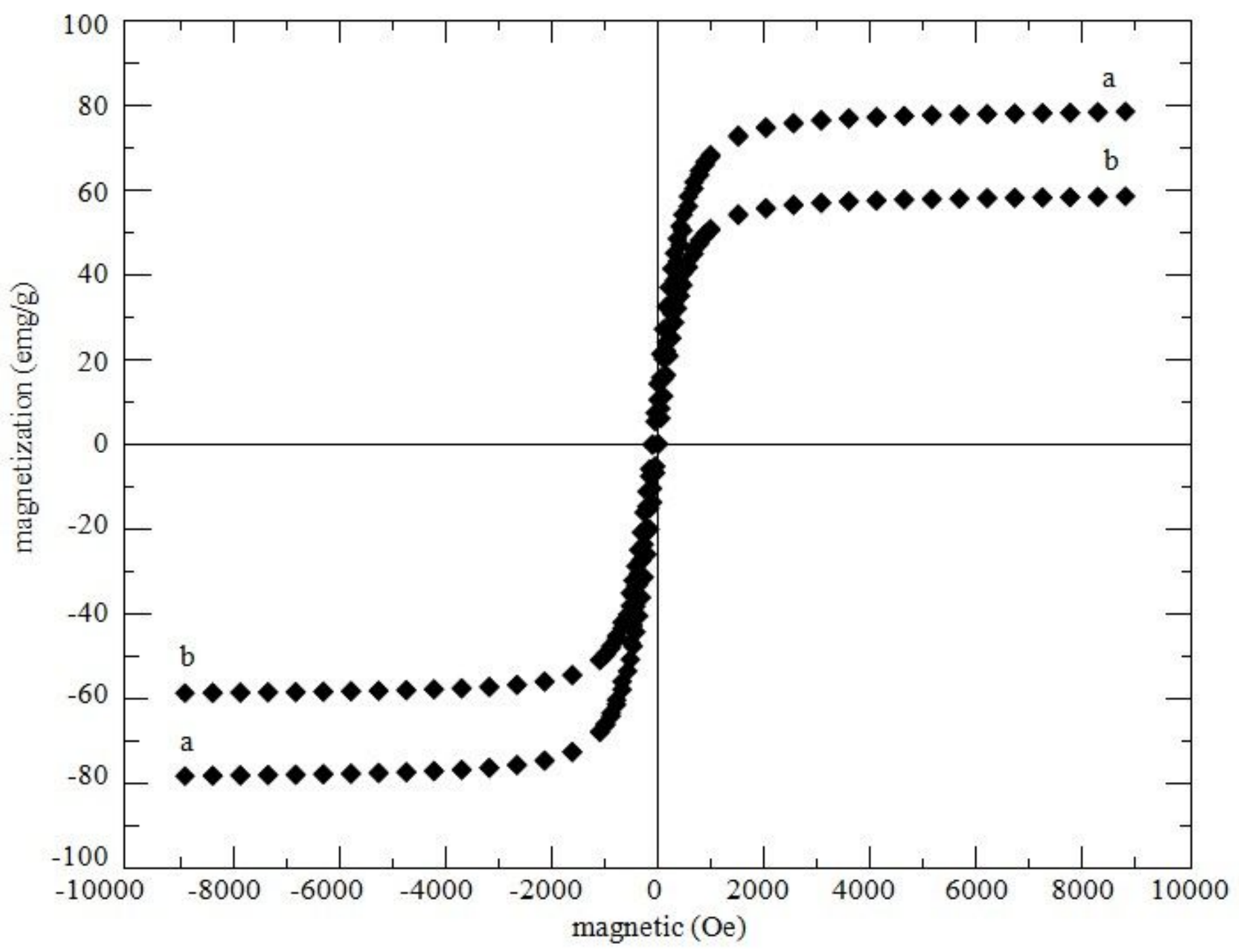

Figure 4

VSM spectrum of MNPs-NH2 (a) and Arg-MDAS (b) 


\section{Pareto Chart of the Standardized Effects}

(response is $\mathrm{C} 12, \alpha=0.05$ )

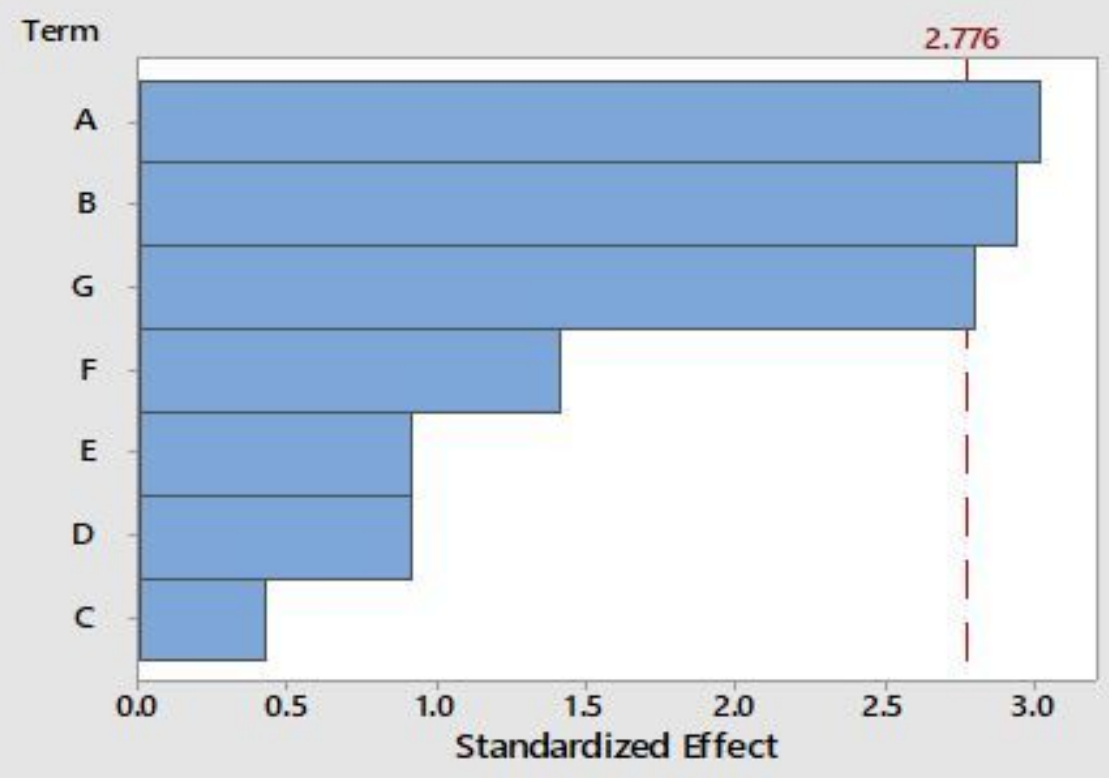

\section{Figure 5}

The standardized main effect Pareto chart for PBD 